\title{
El vuelo icario en la América colonial: relecturas de un mito durante el siglo XVIII en el Perú
}

\section{The icarian flight in colonial America: rereadings of a myth during the eighteenth century in Peru}

Rolando Carrasco M. rcarrascomon@uni-osnabrueck.de Universidad de Osnabrück, Alemania

Cita sugerida: Carrasco M., R. (2021). El vuelo icario en la América colonial: relecturas de un mito durante el siglo XVIII en el Perú. Orbis Tertius, 26(33), e196. https://doi.org/10.24215/18517811e196

\begin{abstract}
Resumen: El ensayo se propone analizar la recepción del "mito de Ícaro y Dédalo” en la América colonial. A partir de la función moralizadora del Ícaro ovidiano como exemplum ex contrario en el discurso festivo y político de inicios del siglo XVIII, el artículo analiza su específica relectura en el debate ilustrado del Perú, mediante el aporte del Cosmógrafo real Cosme Bueno con su "Disertación sobre el arte de Volar" (1790) y el "Nuevo sistema de navegar por los aires" (1762) del limeño Santiago de Cárdenas.
\end{abstract}

Palabras clave: Ícaro, Dédalo, Cosme Bueno, Santiago de Cárdenas, Perú.

\begin{abstract}
This essay aims to analyze the reception of the "Myth of Icarus and Daedalus" in colonial America. Starting from the moralizing function of the Ovidian Icarus as exemplum ex contrario in the festive and political discourse of the early eighteenth century, the article analyzes its specific re-reading in the Enlightenment debate, through the contribution of the royal Cosmographer Cosme Bueno with his "Disertación sobre el arte de Volar" (1790) and the "Nuevo sistema de navegar por los aires" (1762) by Santiago de Cárdenas.
\end{abstract}

Keywords: Ícaro, Dédalo, Cosme Bueno, Santiago de Cárdenas, Perú.

\section{INTRODUCCIÓN}

Dentro del complejo campo de lo que podríamos llamar el estudio de las representaciones y escrituras aviáticas del mundo moderno en Hispanoamérica, resultan casi desconocidos los eventuales aportes de manifestaciones que, desde los tempranos siglos del periodo colonial, nos permitan comprender los precedentes de la conquista simbólica, imaginativa y técnica de los cielos americanos. Cabe advertir que ya para las culturas indígenas del Nuevo Mundo las divinidades aladas o la presencia del mito del vuelo se inscriben en el centro de sus concepciones cosmogónicas. Es el caso de Quetzalcóatl, serpiente emplumada o "serpiente pájaro" en el culto de los aztecas, como también el de Kukulkan para los mayas. En el contexto de las culturas prehispánicas del antiguo Perú, tal como ha planteado Jaime Lara (2016), la presencia del "hombre pájaro" en las evidencias etnográficas y artísticas de las tempranas culturas Chavín y Paracas, así como en las crónicas que registran los relatos sobre el origen de los Incas, nos permiten identificar la leyenda del vuelo de Ayar-Uchu y el brujo Antaki. Estos ejemplos vienen a constitutir un componente de relevacia 
al momento de interrogarnos no solo por la representación y función del vuelo en el sistema de creencias del mundo prehispánico, sino también por la específica recepción de mitos y fábulas de la antigüedad clásica en que la elevación y caída aérea de sus divinidades se integró al campo de la cultura festiva, simbólica y letrada de la tradición colonial en las Américas y el Caribe. Dada la envergadura de esta problemática, el presente ensayo busca sobrevolar de manera particular una de sus manifestaciones más distintivas, el mito de Ícaro y Dédalo y su relación con la modernidad ilustrada (del siglo XVIII) en el contexto andino. Tal como hemos sostenido en otro estudio (Carrasco, 2019), desde el vuelo del joven Ícaro en su huida de la isla de Creta, hasta el célebre Ornitóptero de Leonardo Da Vinci (fines del siglo XV), o los globos aerostáticos de Louis y Joseph Montgolfier en 1783, por mencionar algunos, la inventiva y exploración científico-técnica para el control de los cielos no fue privativa del mundo antiguo ni menos de la Europa moderna, sino también tuvo alcances menos conocidos en el espacio transatlántico de la América colonial hispana y portuguesa. Será en dicho contexto desde donde emerge la interrogante por la recepción del mito de Î́caro y Dédalo en las letras coloniales, pues este constituye un componente de gran relevancia no solo como actualización de la función moralizadora del Ícaro ovidiano (exemplum ex contrario) y condena de la hibris durante el barroco indiano, sino también adquiere un rol singular en el debate ilustrado, gracias al aporte de dos figuras representativas de la cultura dieciochesca en el Perú. Es el caso del cosmógrafo real Cosme Bueno con su "Disertación sobre el arte de Volar" (1790) ${ }^{1}$ y el "Nuevo sistema de navegar por los aires" $(1762)^{2}$ del limeño Santiago de Cárdenas, que abordaremos en el presente ensayo.

\section{El Mito De ÍCARo y DÉDALO: TRADICIÓN CLÁSICA Y CRISIS BARROCA EN AMÉRICA}

El mito de Ícaro y Dédalo, tal como han destacado los aportes críticos de Felix Ingold (1992), LuckHuyse (1997) y Dancourt (2002), es la base de una tradición discursiva en la historia de Occidente que representa la experiencia del vuelo como anhelo trágico y libertario del joven alado, pero también la condición de Dédalo, homo faber, maestro de carpintería, escultor y arquitecto (constructor del laberinto de Creta), inventor de la plástica en la Grecia antigua. Ya desde la Metamorfosis (Libro VIII) de Ovidio, el mito está indisolublemente ligado a los orígenes y progresos de las artes griegas y, según Turner (1976), alcanza una relevante expresión literaria en las letras hispánicas de los siglos XVI y XVII.

Hacia fines del siglo XVIII, el Viage de España (1778) de Antonio Ponz -escrito a instancias de Carlos III y su ministro Campomanes- representa un caso destacado de las continuidades e interpolaciones del mito de Ícaro y Dédalo. Ejemplo de ello es su descripción de la leyenda del llamado "Dédalo Placentino":

El asunto es, que lo que creemos fabuloso en Dédalo, fue un hecho verdadero sucedido en Plasencia. Voló un hombre, y voló un gran trecho.

Es opinión que el tal avechucho [Rodrigo Alemán] fue el que hizo la sillería del coro de la catedral, de cuya caprichosa invención he hablado a. V. Atravesó trepando por los vientos toda la ciudad, desde el castillo, hasta la que llaman Dehesa de los caballos, medio cuarto de legua distante de Plasencia. La causa de este vuelo la cuentan de dos maneras. Dicen unos (y son los del populacho) que lleno de vanidad el artífice de la artillería, prorrumpió en la blasfemia, de que Dios no podía, ni sabría hacerla mejor: que habiéndole puesto preso por tal disparate en una de las torres de la fortaleza, aguzó el ingenio hasta encontrar el modo de salir volando (Ponz, 1778, pp. 129-130).

El proceso de apropiación y retextualización del mito clásico, según José Moráis, ingresa en la literatura española del siglo XVIII, enfatizando la lucha entre "la inspiración divina de los genios y su competición en la creación plástica” (2013, p.153). El sustrato medieval de la condena/caída del volador como transgresión (blasfemia contra Dios), como es de esperarse en el relato de Ponz, concluye con la analogía trágica, pues "lo peor fue que se pareció también a Ícaro en precipitarse" (Ponz, 1778, p.132). La confrontación medieval entre el artífice creador y Dios determina la reinvención del mito de Plasencia en torno a la función del artista no como un creador (condición reservada a Dios), sino como ejecutor. Dicha interpretación, en el marco del escolasticismo de la España medieval, sobrevendrá en una nueva inserción del mito en la tradición 
renacentista y el aporte de Durero, a quien "se debe, entre otros, el traspaso de la creatio ex nibilo de Dios, como capacidad última del Ser humano, al artesano” (Moráis, 2013, p. 157). Con la racionalización del mito en la temprana modernidad ya podríamos atisbar el complejo campo de problematizaciones inherentes a las adaptaciones e innovaciones del mito volador antiguo, en el campo de la teoría del arte de los siglos XVII y XVIII. Téngase en cuenta la importante contribución de Karl Kilinski II (2002) al respecto, ${ }^{3}$ pero, asimismo, el interrogante filosófico en torno a la ciencia, técnica y naturaleza, que animó el racionalismo ilustrado gracias a los tempranos logros de la ascensión aerostática. A mi juicio, he allí uno de los indudables núcleos de teorización que acoge la racionalización del mito, su reformulación estético-filosófica, como también científico-técnica, siendo uno de sus interesantes ejemplos en la tradición europea Le nouveau dédale (1742) de Rousseau.

En el caso de la tradición barroca virreinal, las alusiones al mito clásico abarcan un amplio registro de motivos, representados no solo por Icaro y Dédalo, sino también por la caída de Faetón e Icaromenipo. Ejemplo representativo es el Primero Sueño (1692) de Sor Juana Inés de la Cruz. Tal como han destacado Sabat de Rivers (1977) y Pérez Amador (2015), en este célebre poema las referencias poéticas al fracaso del joven Ícaro en su ascenso al sol, así como el castigo al intrépido Faetón (por su temeraria conducción del carro del Sol a través del cielo), profundizan las connotaciones alegóricas del mito como transgresión, audacia extrema que, finalmente, recibe la condena de la muerte. Vale destacar que dicho campo de significaciones, asimismo, alcanzó un relevante protagonismo mediante el uso del lenguaje emblemático durante los siglos XVII (Sebastián, 1990) y XVIII. Ejemplo de ello es la producción pictórica de Melchor Pérez de Olguín, quien en 1716 reprodujo la entrada del virrey Morcillo en la ciudad de Potosí (Fig.1).

FIG. 1

Entrada del virrey fray Diego Morcillo en Potosí. Melchor Pérez de Olguín (1716)

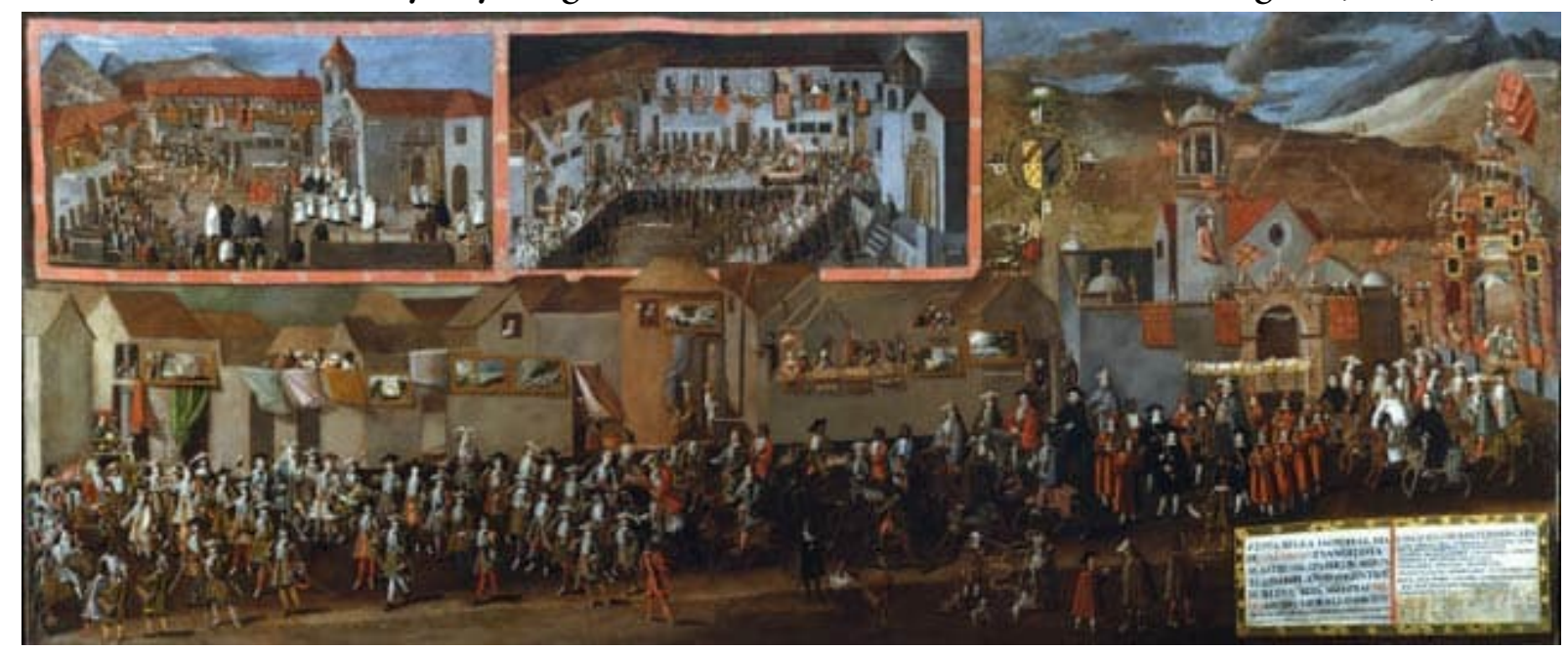

Kagan, R.; Mariás, F. (2000). Urban images of the Hispanic world 1493-1793. New Haven: Yale Univ. Press 
FIG. 2

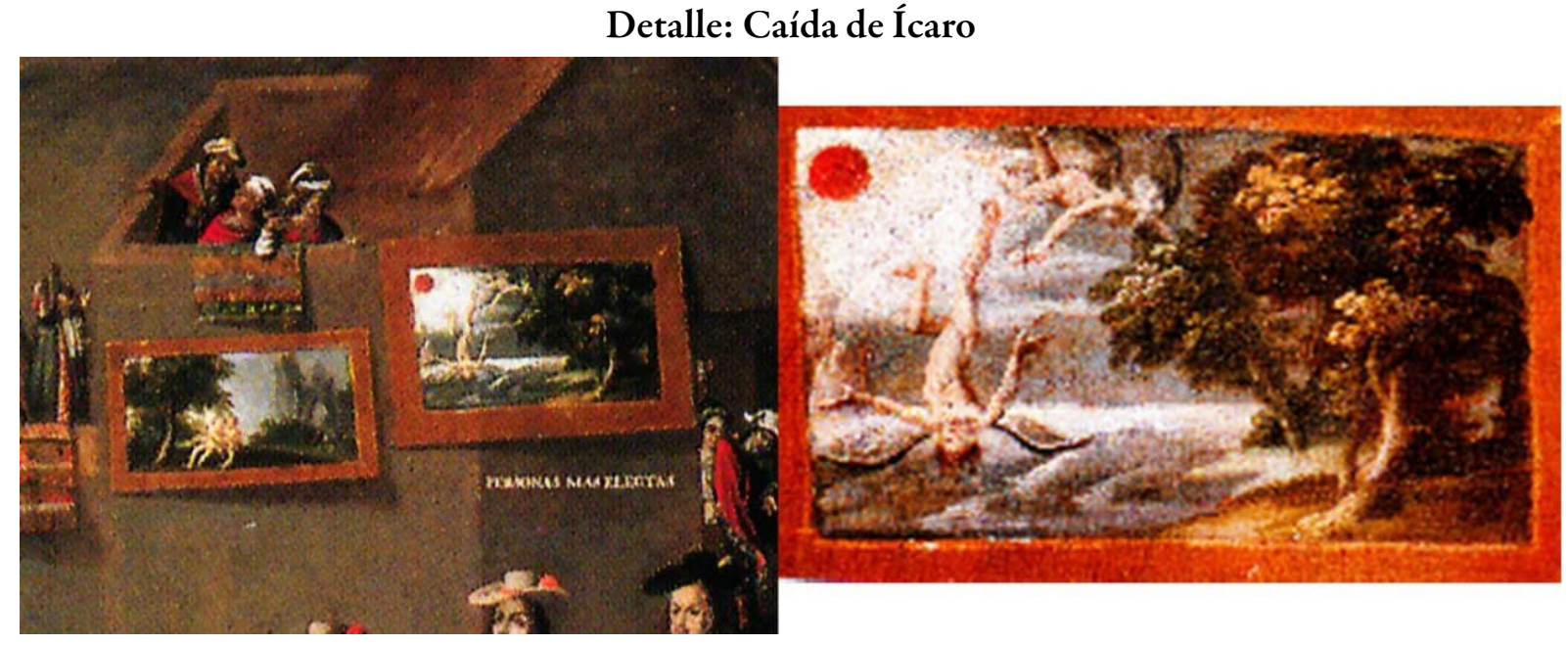

Tal como ha señalado Lucía Escobari, la representación de esta festividad pública al nuevo Virrey del Perú se daba en momentos de la peor situación productiva de las minas de Potosí, sin embargo, para la composición de los arcos, pinturas emblemáticas o alegóricas, su coreografía u orfebrería, al parecer no se escatimó en gastos. El programa de escenas alegóricas en sus arcos triunfales dispuestos a la entrada de la ciudad se inspira en una emblemática moral con base en tres conceptos: urbanidad, liberalidad y fama (2011, p. 151). De mayor interés para nuestro problema es el uso de siete pinturas colgadas en las paredes de las casas, destacando en dicho conjunto la caída de Ícaro en el vuelo con su padre Dédalo (Fig. 2). Precisa Escobari:

La imagen de Ícaro cayendo hace referencia a la ambición, siempre buena en su justa medida. Así como Ícaro no debía volar ni muy alto ni muy bajo, así pues su relato mitológico nos refiere a una máxima moral de conducta. Alciato la dispone en su emblema 53 con el texto: Ícaro que subir hasta el sublime / cielo queriendo, dentro el mar caíste: / mira que aquella cera aquí te imprime / de quien antes de ahora muerto fuiste, / para que por tu ejemplo más se estime / la sciencia por la cual tú te perdiste. / Mas nadie juzgue hasta que lo entienda / porque caerá soltando más la rienda (2011, p. 152).

Esta retórica visual y emblemática con su juego de significados alegóricos -completada por otros lienzos mitológicos que adornan la entrada del Virrey: Eros y Anteros, Mercurio y Argos, el sueño de Edimión, el Coloso de Rodas, la muerte y, finalmente, Eneas y Anquises- acentúa el alcance del Speculum principis (Espejo de príncipes) en el programa político imperial en América hacia inicios del siglo XVIII: alabar y exigir. ${ }^{4}$ La presencia de Ícaro y Dédalo en la composición emblemática preparada para la recepción del nuevo virrey-arzobispo formó parte de la cultura festiva y el aparato iconográfico en que el vuelo icario actualiza el mensaje político de un «buen gobierno» guiado por la mesura y la censura de la ambición humana. Cabe advertir que las proyecciones del mito no fueron exclusivas de esta retórica festiva y ritual en torno al poder colonial, sino también constitutivas de la lírica virreinal del siglo XVII (con Juan del Valle y Caviedes, Diego Dávalos Figueroa, José Bermúdez de la Torre y Solier o Pedro Peralta Barnuevo, entre otros). ${ }^{5}$ Junto a estas manifestaciones, no menos significativas habrían de ser las expresiones religiosas y devocionales del barroco andino, como fuera el caso del imaginario alado de un San Francisco (Lara, 2016, pp. 147-213), los ángeles del Apocalipsis, demonios o arcángeles arcabuceros, estudiados por Ramón Mujica Pinilla (1996, 2013).

A partir de esta particular función del vuelo icario en el discurso emblemático de inicios del siglo XVIII, en lo que viene del artículo me interesa contraponer otras modulaciones aviáticas de la Ilustración en el Perú, considerando de manera particular la actualización y polifuncionalidad discursiva del mito en la obra de Cosme Bueno y Santiago de Cárdenas. 


\section{Francisco Cosme Bueno frente al ingenio técnico de un dédalo limeño}

El advenimiento de la Ilustración y el sapere aude kantiano romperían con las barreras del dogmatismo escolástico y la retórica barroca, abriendo paso al enciclopedismo dieciochesco con su carga de racionalismo, sentido crítico y desarrollo del saber científico-técnico y experimental, entre otros, gracias a los viajeros científicos por la América colonial. Los nombres de Louis Godin, Jorge Juan, Antonio de Ulloa y Charles Marie de la Condamine están ligados, según Mary Louise Pratt (1992), a la expedición geodésica hispanofrancesa (1735-1744) como a la emergencia de una "conciencia planetaria" y el triunfo de la ciencia europea. ${ }^{6}$ Sin embargo, una perspectiva distinta es la que nos entrega una carta del Mercurio Peruano (8 de enero de 1792), en que, a mi juicio, se reconocen los términos de un nuevo paradigma de comprensión del vuelo icario por parte de la conciencia criolla:

Se arrojaba el Ícaro del siglo Mr. Carlos [La Condamine] desde las orillas del Sena a romper las ráfagas del ayre en medio de los aplausos de un pueblo numeroso: y quando ya no escuchaba las proclamaciones de quatrocientas mil personas: quando ya París había desaparecido de sus ojos: quando los Alpes y los Pirineos se habían aniquilado: quando la Europa entera solo figuraba un tosco borrón que empañaba el horizonte; Mr. Carlos creyó haber salido del turbillón de la tierra, y se preparaba a surcar el de la Luna! Mortal atrevido, e ignorante, en esa región elevada aun no has excedido el nivel del pavimento del alto Perú! (Fol. 21-22).

La perspectiva crítica sobre este Ícaro francés, al contraponer las observaciones barométricas de los Andes con las elaboradas por La Condamine, expone un complejo campo de tensiones epistémicas y simbólicas en tiempos del reformismo borbónico. Nuestro anónimo "filósofo peruano", a la par que fundamenta "la predilección de la naturaleza a favor del Perú" (Fol. 22), contradice los prejuicios de la visión eurocéntrica sobre la falta de cultura y la condición degradada de la naturaleza americana (De Paw, Buffon, Raynal), según el célebre "Debate del Nuevo Mundo" abordado por Antonello Gerbi en 1955. Su perspectiva expone el proyecto científico en el Perú que, junto a las observaciones de la Astronomía y las demostraciones de la Física para el estudio del globo terráqueo, está al servicio de la "patria”. Considero que entre la alegorización barroca del mito alado - con su fuerte carga simbólica de corte teológico-moral- y la función satírica en esta caída aeroespacial del Ícaro francés, se inscribe un fenómeno de reactualización del mito alado, gracias a una nueva conciencia crítica criolla (o con una perspectiva criollizada) en el campo de la ciencia y la técnica americana. El proyecto patriótico de este ilustrado americano se nutre en su carta de la utilidad de los nuevos saberes (astronomía, física, mecánica, meteorología, química, etc.), que habrían de alcanzar un momento cúlmine en la conquista aeronáutica de la Europa moderna, gracias a la inventiva de los globos aerostáticos y la navegación de Louis y Joseph Montgolfier en 1783, como de sus avistamientos en las colonias de Santo Domingo y Oaxaca, según testimonian las investigaciones de McClellan (1992) y González Claverán (1987), respectivamente.

Además de este ejemplo de la prensa ilustrada en la América colonial, menos conocido resulta el aporte del médico aragonés Cosme Bueno en torno al vuelo. ${ }^{7}$ Catedrático de Prima de matemáticas de la Real y Pontificia Universidad de San Marcos y Cosmógrafo Mayor del Virreinato del Perú, fue célebre por la composición de sus almanaques anuales (Conocimientos de los tiempos), pero también por la publicación de disertaciones físico-médicas como clara expresión del enciclopedismo dieciochesco en las letras de América. Ejemplo de ello sería su ensayo "Disertación sobre el arte de Volar", publicado en el Conocimiento de los tiempos de $1790 .{ }^{8}$ Resulta de gran interés destacar que la reflexión aeronáutica de esta "Disertación” no es un fenómeno aislado. Otro ejemplo es el manuscrito anónimo (lamentablemente extraviado) Viaje al globo de la Luna (1790) que, según lasCrónicas Potosinas de Omiste, incluyó un comentario sobre las posibilidades de la navegación aérea, refiriendo algunas de sus páginas (Cap. I) a la invención de Santiago de Cárdenas el "Volador". Según Omiste, muy valorados son dos capítulos de esta fuente que se consagran a "los sistemas para beneficiar metales, datos sobre las minas de azogue de Huancavelica, descripción del lago Titicaca, 
opinión sobre su desagüe, posibilidad de una inundación espantosa, y pormenores sobre las minas de Puno y Potosi’" (1919, p. 260). ${ }^{9}$ Más allá del carácter misceláneo y sugerente título de Viaje al globo de la Luna, ${ }^{10}$ a mi juicio, no fue la mera curiosidad lo que pudo haber llevado a compilar las informaciones sobre la minería potosina y de Huancavelica, junto al diseño de una particular máquina voladora. El discurso en torno a la máquina y la técnica son elementos portadores de los idearios de la utopía ilustrada en tiempos del reformismo borbónico en el Perú, en el que, tras los esfuerzos por incrementar la producción minera, se identifican necesidades específicas de la corona y los intereses creados por los propios mineros locales y el protonacionalismo peruano. Tal como ha demostrado Kandal Brown, la intervención estatal durante el siglo XVIII contribuyó a generar una próspera "Edad de la Plata" en Huancavelica:

Huancavelica recibió bastante atención de los ministros reformistas borbónicos, que aspiraron a elevar el nivel tecnológico de las minas de azogue y a satisfacer la creciente demanda por el mercurio. Después de 1720 la producción peruana de plata empezó a aumentar levemente, llegando a un total de 86,8 millones de pesos entre 1791 y 1800, una cantidad mucho mayor que la producida durante los años legendarios de Potosí de comienzos del siglo XVII (1995, pp. 60-61).

De las tres fases que distingue Brown para las reformas borbónicas en el Perú, muy especialmente nos ha de interesar la tercera que se inicia en 1781. Dicho periodo -concordante con el contexto de producción del anónimo Viaje al globo de la Luna y la "Disertación sobre el arte de Volar"- se distinguió por la intervención de ingenieros como de expertos europeos para introducir las tecnologías más recientes en la América meridional (Brown, 1995, pp. 65-66). Ejemplo de ello es la acción del perito sueco en mineralogía y metalurgia, el barón de Nordenflicht, contratado por Carlos III para encabezar una expedición que iría al Perú con la finalidad de elevar el nivel tecnológico de la producción. Este suceso dio inicio a un proceso de transferencias científico-técnicas, gracias a la iniciativa hispano-sajona que encontraría oposición entre españoles y criollos. Tal esfuerzo de colaboración, muy probablemente, también deba su origen a la recepción en Europa de las noticias sobre el Perú, gracias a la traducción parcial al alemán del Mercurio Peruano (Peru, nach seinem gegenwärtigen Zustande dargestellt aus dem Mercurio Peruano,1807-1808), mediante la colección que el barón Alexander von Humboldt enviara a Goethe en Weimar. ${ }^{11}$ En el marco de este contexto de transformaciones científico-técnicas, cabe preguntarnos qué habría determinado la inclusión de la navegación aérea y, en particular, de Santiago Cárdenas (1726-1766) con su memorial "Nuevo sistema de navegar por los aires"12 en un manuscrito como el Viaje al globo de la Luna.

En 1761 este cuarterón limeño presentó un memorial al Virrey Don Manuel de Amat y Juniet, solicitando recursos para la fabricación de su máquina de volar, nacida de la observación de gallinazos y cóndores. ${ }^{13}$ Sería el propio Cosme Bueno quien en 1768 debería informar al virrey Amat sobre la inventiva del apodado "El Volador" o "El Pajarero", así como de su "máquina” para los “correos volátiles" entre Lima y Madrid en el contexto de la guerra que declaró Inglaterra a España, cuando el gobierno de Buenos Aires trató de desalojar a los ingleses de Puerto Egmont (Islas Malvinas):

Como era consiguiente que se turbase la regular comunicación de este reino con la Metrópoli, propuso a este superior gobierno un sujeto de bajo carácter, aunque no de bajo ingenio y habilidad, que en poco tiempo la continuaría por el aire, llevando y trayendo pliegos con mucho beneficio del rey y del público (Bueno, 1872, p. 261).

La "Disertación”(1790) de Cosme Bueno, publicada casi tres décadas después del Memorial (1761) de Cárdenas y su "Nuevo sistema de navegar por los aires"(1762), ${ }^{14}$ representa el afán de divulgación y popularización de las ciencias en el siglo XVIII limense, debatiendo en su "Primera parte" (1872, pp. 262-269) sobre los tempranos avances e inventos de los siglos XVII y XVIII sobre la navegación aérea; así como en su "Segunda parte" (pp. 269-277) sobre la imposibilidad de tal empresa humana. No debemos olvidar que la inclusión de esta "Disertación" en el almanaque de 1790 responde al afán didáctico y divulgador de la ciencia entre los lectores peruanos. En dicha perspectiva, resulta innegable que más allá de la viabilidad de 
este invento de "El Volador", el memorial de Cárdenas influyó en el debate dieciochesco sobre la navegación aérea.

FIG. 3

Nuevo sistema de Navegar por los aires

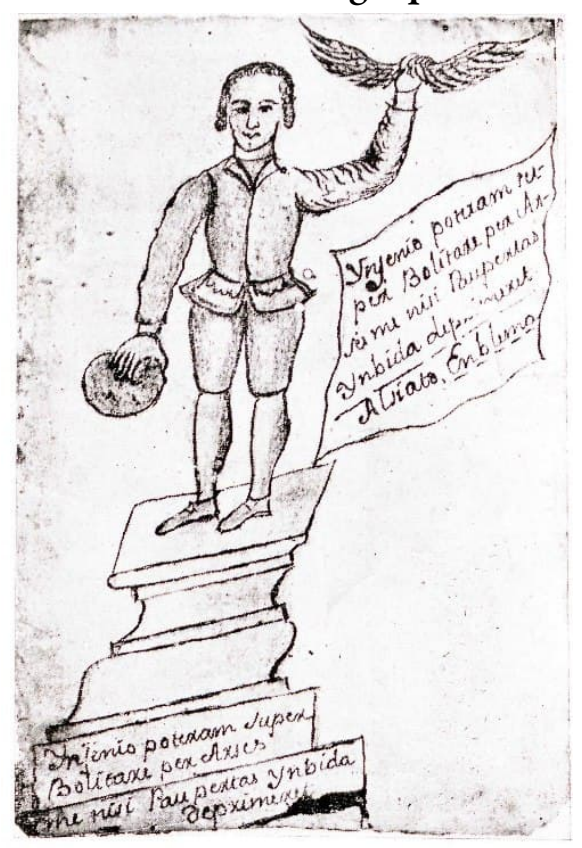

Cárdenas, S. (1937 [1762]). Nuebo sistema de nabegar por los aires sacado de las obserbaciones día naturalesa bolatil. Lima: Torres Aguirre.

Si hemos de considerar la propia fuente de Santiago de Cárdenas, "Nuevo sistema de navegar por los aires" -cuyo emblema aquí reproducimos (Fig. 3)-, su énfasis en un origen humilde como cuarterón empobrecido, ${ }^{15}$ perteneciente al gremio de sombrereros, así como su destreza en "barios oficios mecánicos" (Cárdenas, 1937, pp. 13-14) tienen una singular función contradiscursiva frente al negativo veredicto de Cosme Bueno, actualizando el mito de Ícaro, pero ahora desde la clara defensa del Dédaloartesano, tal como reconocemos en la Objeción cuarta de su texto, gracias al empleo del diálogo didáctico entre el Maestro (Cóndor) y su Discípulo (Cárdenas):

D. Se me a dicho que intento renobar la fabula de Icaro oponerme al Autor de la Naturaleza y que pensar en tal es perder tienpo.

C. A que respondio que de Icaro se dise como fabula y en tal sentido se entiende la moralidad pero si se refleciona en el orijen de la fabula y el principio, que tomaron los Poetas, para colorir su dictamen se allara en Dédalo, un hombre de Grande Imperio, pues en el tiempo de la Esterilidad, quiero decir, cuando sus Inbentos no tenian el cultibo de las ciencias, ni la ficica, daba el Ajito a su mobimiento, este inbento la sierra y el sepillo ambos instrumentos tan utiles, como necesarios....

Porque Dédalo Bolaba seguro i Icaro sello con su nombre las Aguas por que este Boló Alto y el otro Bolaba bajo. Con que si se da alguna fe a la fabula se alla en Dédalo Berificado el excito... (Cárdenas 1937, pp. 80-81).

Cárdenas reinstala la reflexión sobre la observación natural de las aves, la inventiva y el dominio técnico de su experimento volador como un Dédalo peruano. Desplaza la retórica barroca de la imprudencia voladora, la pretensión exorbitada y pecaminosa de Ícaro, por el mérito ingenioso del homo faber indiano. Pese a la "baja condición" de su origen, argumenta Cárdenas, "no se opone al atributo de todo Criador que se de a los hombres que vuela o quiera volar" (p. 82). La argumentación del cuarterón limeño, a mi juicio, es una interpelación directa al rechazo con que Cosme Bueno (en 1790) nuevamente sentenciaría la tentativa de su arte de volar con alas. En su "Disertación", el categórico argumento del Cosmógrafo Mayor sobre la imposibilidad humana de "imitar la naturaleza" (Bueno, 1872, p. 276) no solo puede interpretarse como una 
reafirmación de un orden y jerarquía divinos y los peligros de la "imitación”, pues, como éste señala, frente al "Supremo Creador" los esfuerzos por remontar los cielos serán siempre vanos e insensatos (p. 277). Pese a ello, bajo la perspectiva de este artesano y observador de tijeretas y cóndores, late la defensa de una episteme americana que reinscribe la fábula y caída alada. Por un lado, mediante la actualización del mito desde un "locus" de enunciación subalterno y como "Gloria de mi Patria, Lima". ${ }^{16}$ Por otro, gracias a la relevancia del "artesano" y su saber americano como un dédalo limeño. A este respecto, encontramos gran pertinencia en la observación de Nieto Galán, en torno al desarrollo de la técnica y la ciencia:

Se conservan numerosas autobiografías de artesanos: memorias, diarios personales, crónicas familiares, cuadernos de viajes, etc. Sus opiniones, argumentos y formas de escritura cuestionan esa imagen subalterna y marginal de esos grupos, que tanto ha influido en nuestra apreciación de la cultura contemporánea. En esas narraciones, la dignidad del artesano y sus habilidades manuales se resiste a ese trágico destino de Ícaro, el bijo de Dédalo, que de forma imprudente, al querer volar demasiado alto, dejó fundir la cera que sostenia las plumas de sus alas fabricadas por su padre. Los artesanos de los talleres, arsenales o boticas consideraban las operaciones allí efectuadas como una forma de conocimiento en si misma, que nada tenía que ver con la obsesión individualista del genio creador, sino que estaba más bien dirigida a la sensación de perfección duradera de la obra realizada gracias precisamente a la cooperación, al esfuerzo conjunto de todos lo miembros del taller (2011, p. 215. Lo destacado es mío).

El debate Cárdenas-Bueno, así como es una de las más preclaras manifestaciones de la dualidad epistémica con que convendría revisar esta(s) Ilustración(es), en plural, durante el siglo XVIII en la América colonial, también exige reconsiderar el aporte técnico de inventores, ingenieros o artesanos en la revolución de la ciencia moderna; la que no puede explicarse, en término de Nieton Galán, "sin la hipótesis de una estrecha colaboración entre el mundo académico y el artesano, entre los filósofos y las máquinas, entre los razonamientos abstractos y el talento de los constructores de instrumentos o los fabricantes de los más diversos materiales" (2011, p. 211).

El menosprecio de Cosme Bueno por el trabajo manual y la inventiva del Dédalo limense representan una llamada de atención no solo sobre el escolasticismo argumentativo de su "Disertación”, pues: "Dios (...) puso para nuestra conservación entre nuestro elemento, y el de las aves un coto invencible, un muro inexpugnable, que no destruirán jamás, por más máquinas que inventen la industria y el poder” (1872, p. 277), sino también sobre un doble componente discursivo. Por un lado, la frontera epistémica y racial del mundo colonial con su sociedad de castas; y, por otro, entre técnica indiana y ciencia moderna, a través de la obliteración de saberes subalternos como el de Santiago de Cárdenas, un protagonista más en la emergencia de la conciencia americana del arte de volar. En dicha perspectiva, la sentencia final del médico y matemático Cosme Bueno, para el cual "si hubiera uno que llegara a alcanzar este imposible, debería ser arrojado del mundo antes que propagara un arte tan fatal y tan pernicioso" (1872, p. 277), testimonia la hibris del erudito sanmarquino y la censura epistémica de esta colonialidad del saber frente al aporte inventivo o técnico americano, el cual, o bien sería rechazado o estandarizado, según las nuevas concepciones tecnológicas europeas que ingresarían (por ejemplo, en la explotación minera o producción metalúrgica) mediante ingenieros, sabios y expertos del Viejo Mundo, según testimonia Viaje al globo de la Luna.

\section{CONCLUSIONES}

El mito de Ícaro y Dédalo ocupa un lugar destacado en el campo de las visiones aeroespaciales de la cultura virreinal. Tal como se identificara en la recepción del Virrey Amat en el Perú, la particular escenificación del mito en este contexto festivo como político hacia inicios del siglo XVIII refuerza el simbolismo alegórico y barroco del Ícaro ovidiano, en tanto castigo de la osadía y soberbia de aquel que intente alcanzar las impenetrables alturas solares. Sin embargo, cabe reconocer que la disputa simbólica y científico-técnica de los cielos es un elemento que ya podemos reconocer en el Mercurio Peruano (1791) y la autoafirmación de una conciencia criolla con su sátira aeroespacial en la caída del Ícaro francés (La 
Condamine). De manera particular, en el caso de la "Disertación" de Cosme Bueno y el "Arte de volar" de Santiago de Cárdenas, la recepción del mito alado no solo nos ha permitido identificar la abierta reivindicación del ingenio artesanal y técnico del Dédalo peruano como sujeto y saber subalternos, sino además la forma cómo el mito se inscribe en un contexto de producción americano en que se hacen evidentes las profundas tensiones (teológicas, científico-técnicas) y diferencias del mundo colonial en el marco de las fronteras raciales y epistémicas que convergen en el discurso sobre el vuelo icario durante el reformismo borbónico en el Perú del siglo XVIII.

\section{REFERENCIAS}

Brown, K. (1995). La recepción de la tecnología minera española en las minas de Huancavelica, siglo XVIII. En M. Cueto (Ed.), Saberes andinos. Ciencia y tecnología en Bolivia, Ecuador y Perú (pp. 59-90). Lima: Instituto de Estudios Peruanos.

Bueno, C. (1872 [1790]). Disertación sobre el arte de Volar. En M. de Odriozola (Comp.), Colección de Documentos Literarios del Perú Vol. III(pp. 261-277). Lima: Imprenta del Estado.

Cárdenas, S. (1878 [1762]). Nuevo sistema de navegar por los aires: sacado de las observaciones de la naturaleza volatil. Santiago de Chile: Rafael Jover.

Cárdenas, S. (1937 [1762]). Nuebo sistema de nabegar por los aires sacado de las obserbaciones día naturalesa bolatil: 1762. Lima: Torres Aguirre.

Carrasco, R. (2019). Globos y artefactos de volar en la América colonial. La conquista ilustrada del espacio celeste en los siglos XVIII y XIX. En C. Strosetzki (Ed.), Aspectos actuales del hispanismo mundial (pp. 603-619). Berlin/ Munich/Boston: De Gruyter.

Colombí-Monguió, A. (1998). Poética en clave de sol. El saber omnicomprensivo en la poesía colonial. Calíope: journal of the Society for Renaissance and Baroque Hispanic Society, 4(1-2),139-156.

Dancourt, M. (2002). Dédale et Icare: Métamorphoses d'un mythe. Paris: CNRS Editions.

Escobari, L. (2011). El programa emblemático alegórico en la entrada del virrey Morcillo a Potosí en 1716. En La fiesta. Memoria del IV Encuentro Internacional sobre Barroco (pp.149-157). Pamplona, Fundación Visión Cultural/ Servicio de Publicaciones de la Universidad de Navarra. Recuperado de https://dadun.unav.edu/bitstream/10 171/18478/1/16_Querejazu.pdf

Gerbi, A. (1982 [1955]). La disputa del Nuevo Mundo. México: Fondo de Cultura Económica.

González Claverán, V. (1987): Globos aerostáticos en la Oaxaca del siglo XVIII. Quipu, 3, 387-400.

Hopkins Rodríguez, E. (2010). Teatralización y racionalidad en la poesía religiosa de Juan del Valle y Caviedes. En J. Olivares (Coord.), Eros divino: estudios sobre la poesia religiosa iberoamericana del siglo XVII (pp. 409-420). Zaragoza: Prensas Universitarias de Zaragoza.

Ingold, F. (1992). Der Autor im Flug. Daedalus und Ikarus. Könnerschaft und Inspiration“ En Der Autor am Werk. Versuche über literarische Kreativität (pp. 11-30). München: Carl Hanser Verlag.

Kilinski, K. (2002). The flight of Icarus throught Western Art. Lewiston/Queenston/Lampeter: The Edwin Mellen Press.

Lara, J. (2016). Birdman of Assisi: Art and the Apocalyptic in the Colonial Andes. Tempe, AZ: Arizona Center for Medieval and Renaissance Studies / Bilingual Press Editorial Bilingüe.

Lévano Castillo, F., Gonzáles Jáuregui, T. y Valdivia Acuña, M. (2003). La aviación civil en el Perú. Lima: Universidad Alas Peruanas / Aero Club del Perú.

Luck-Huyse, K. (1997). Der Traum vom Fliegen in der Antike. Stuttgart: Franz Steiner Verlag

McClellan III, J. (1992). Colonialism and Science: Saint Domingue and the Old Regime. Baltimore: Johns Hopkins University Press.

Mercurio Peruano. Tomo IV (8 de enero de 1792). Recuperado de http://www.cervantesvirtual.com/obra-visor/mer curio-peruano--18/html/027f5ec8-82b2-11df-acc7-002185ce6064_42.html 
Moráis, J. A. (2013). Cuando Ícaro voló sobre Plasencia. El comentario a la Eneida de Fray Juan Luis de la Cerda y las reelaboraciones de un mito medieval. Troianalexandrina, 13, 143-168.

Morales Cama, J. M. y Morales Cama, M.A. (2010). La ilustración en Lima: vida y obra del doctor Cosme Bueno y Alegre (1711 -1798). Lima: Morales Cama.

Mujica Pinilla, R. (1996). Angeles apócrifos en la América virreinal. Lima \& México: Fondo de Cultura Económica.

Mujica Pinilla, R. (2013). Angels and demons in the conquest of Peru. En F. Cervantes y A. Redden (Eds.), Angels, demons and the New World (pp. 171-210). Cambridge: Cambridge University Press.

Nieto-Galan, A. (2011). Los públicos de la ciencia: Expertos y profanos a través de la historia. Madrid: Marcial Pons Historia Estudios.

Núñez, E. (1936). La versión alemana del «Mercurio Peruano». Boletín Bibliográfico. Biblioteca de la Universidad Mayor de San Marcos, 6 (1), 27-30.

Omiste, M. (1919). Crónicas Potosinas. Estadísticas, biográficas, notas históricas y políticas. Vol. I. La Paz: González y Medina.

Palma, R. (1996). Santiago, el Volador. En J. Ortega y F. M. Rodríguez-Arenas (Eds.), Tradiciones peruanas (pp. 161-165). Madrid/París: ALLCA XX.

Pérez-Amador, A. (2015). El precipicio de Faetón: Nueva edición y comento de "Primero Sueño" de Sor Juana Inés de la Cruz. Frankfurt am Main: Vervuert.

Peru, nach seinem gegenwärtigen Zustande dargestellt aus dem Mercurio Peruano. Friedrich Justin Bertuch (Ed.). Weimar, Landes-Industrie-Compt., 1807-1808. Recuperado de https://babel.hathitrust.org/cgi/pt?id=nyp.334 330816988668 view $=1$ up\&seq $=1$

Ponz, A. (1778). Carta VI. En Viage de España, ó Cartas, en que se da noticia de las cosas mas apreciables, y dignas de saberse que hay en ella. Vol. 7(pp. 129-146). Madrid: D. Joachin Ibarra. Recuperado de http://bdh-rd.bne.es/v iewer.vm?id $=0000154545 \&$ page $=1$

Pratt, M. L. (1992). Imperial Eyes: Travel Writing and Transculturation. New York: Routledge.

Ramírez Rivera, H. (1996). El Cosmógrafo Mayor don Cosme Bueno y su obra "El Conocimiento de los Tiempos". Revista de Geografia Norte Grande, 23, 109-111. Recuperado de https://repositorio.uc.cl/xmlui/bitstream/han dle/11534/10412/000152043.pdf

Sabat de Rivers, G. (1977). El «Sueño» de Sor Juana Inés de la Cruz: tradiciones literarias y originalidad. London: Tamesis Books.

Sebastián, S. (1990). Un renovado humanismo: la emblemática. En El barroco iberoamericano.Mensaje iconográfico (pp. 249-288). Madrid: Ediciones Encuentro.

Smith, A. (1839). Peruas It Is: A Residence in Lima, and Other Parts of the Perwvian Republic. London: Richard Bentley. Recuperado de https://archive.org/details/peruasitisaresi00smitgoog/page/n576/mode/2up?q=Santiago

Stucci, L. y Stucci, M. (2019). Navegar por los aires. Análisis físico y biológico del sistema propuesto por Santiago de Cárdenas en el siglo XVIII. Lima: Fondo Editorial de la Universidad del Pacífico.

Turner, J. H. (1976). The Myth of Icarus in Spanisch Renaissance Poetry. London: Tamesis.

\section{Notas}

1 En adelante citaremos la "Disertación sobre el arte de Volar" de Cosme Bueno, según la edición de Odriozola (1872).

2 Todas las citas de "Nuevo sistema de navegar por los aires" corresponden a la edición de 1937. Se mantiene la ortografía original. Adicionalmente se consigna en la bibliografía general la edición de 1878 (Santiago de Chile).

3 Ver especialmente el capítulo IV de su estudio: "Of Myth and Mortals: Allegory and Nature in the 17th and 18th Centuries" (2002, pp. 219-298).

4 A este respecto, véase el artículo de Escobari (2011, p. 154).

5 A este respecto, véanse las referencias a Ícaro en la poesía de Juan del Valles y Caviedes (Cf. Hopkins, 2010). Alicia de Colombí-Monguió (1998) ha abordado el “pensamiento icario" en la lírica de Agustín de Salazar y Torres y Diego Dávalos (Miscelánea Austral, 1602). Para el caso del siglo XVIII, destácase el criollo peruano José Bermúdez de la Torre y 
Solier con su El sol en el Zodíaco (1717), el Icaromenipo lucianesco del polígrafo Pedro Peralta Barnuevo o la producción poética barroca del quiteño Juan Bautista Aguirre.

6 Véase, especialmente, el Cap. 2. de la obra de Pratt: "Science, planetary consciousness, interiors" (1992, pp. 15-37).

7 En relación con el aporte de Cosme Bueno a la Ilustración americana del siglo XVIII, veánse los estudios de Ramírez Rivera (1996) y Morales Cama (2010).

8 Completan este breve registro de Cosme Bueno sus "Disertaciones sobre los antojos de las mujeres preñadas (1794), además de una "Disertación Experimental sobre la Naturaleza del Aire y sus Propiedades" (1796).

9 Según el historiador boliviano, los capítulos V y VI que completan la obra contienen noticias científicas y literarias (teorías sobre las mareas, desviaciones de la aguja, vientos, una disertación sobre el teatro y la poesía dramática). Se conjetura un probable origen español del manuscrito y residencia de su autor por varios años en el Perú.

10 Ricardo Palma en sus Tradiciones peruanas (1996) también registra el manuscrito: Viaje al globo de la Luna ocasionado con el descubrimiento de la Máquina aerostática. Historia prodigiosa por sus raras ocurrencias y útil por sus importantes hallazgos. En que por un método curioso y espectable se tratan con much a novedad las materias más arduas y dificiles de resolver de varias artes y ciencias, especialmente en la física. (c. 1790?), a la fecha, desaparecido. En relación con el título de este manuscrito, recuérdese uno de los aportes clásicos de la llamada literatura de ciencia ficción y el viaje a la luna en el siglo XVII, L'Autre Monde ou les Estats et Empires de la lune (1657) de Cyrano de Bergerac.

11 Tal como ha documentado Estuardo Núñez, el secretario particular de Carlos Augusto (Duque de Sajonia, WeimarEisenbach) era Friedrich Justin Bertuch (1747-1822), quien sería además el traductor del Quijote al alemán y editor de Peru, nach seinem gegenwärtigen Zustande dargestellt aus dem Mercurio Peruano. Weimar, 1807-1808. Cf. Núñez (1936).

12 El manuscrito original desapareció en el incendio de la Biblioteca Nacional de Lima, pero ha quedado una transcripción elaborada por la Delegación peruana a la I Conferencia internamericana de Aviación. Cardenas, a los 36 años, escribió un segundo memorial en el que expone la idea de una máquina voladora, dedicando su obra a los patriotas de Lima durante los años 1750-1762. En lo que sigue, todas las citas pertenecen a la edición de 1937. La Biblioteca Nacional de Chile registra además una edición del Nuevo sistema de navegar por los aires (1878). Por último, destacamos la reciente edición y estudio de Luciano Stucci y Marcelo Stucci: Navegar por los aires. Análisis físico y biológico del sistema propuesto por Santiago de Cárdenas en el siglo XVIII(2019).

13 Según Lévano Castillo (2003): "El texto ["Nuevo sistema de navegar por los aires”], aparentemente está estructurado para responder en consecuencia, al orden en que fueron presentadas las observaciones a su propuesta del primer memorial (5 de noviembre de 1761), por parte del Catedrático de Matemáticas Dr. Cosme Bueno. Primero se dirige al lector para introducirlo en la materia de su solicitud, luego explica las láminas con los diversos dibujos. En esta parte dirigida al lector, menciona que su trabajo es presentado acompañado de dos memoriales al virrey don Manuel Amat, uno el 5 de noviembre de 1761 y el otro el 6 de diciembre de 1762, con el propósito de: “... conseguir el descubrimiento de haser nabegable el Aire,...” (p. 10).

14 Hacia 1839, Archibald Smith, en Peru as It Is: A Residence in Lima, and Other Parts of the Peruvian Republic, aún registra la circulación de la obra de Santiago Cardenas y su aporte a la ornitología andina: "Santiago Cardenas, better known by the name of Santiago el Volador, or Flier, for many years watched the flight of the condor, with the intention of imitating him; and he left a quarto volume written on this subject, which I have deposited in the library of the College of Sda Fernando. In this work he describes three different kinds of condor" (1839, p. 256).

15 El más reciente aporte de Stucchi y Stucchi (2019), finalmente, permite clarificar esta interrogante en torno al origen étnico de Santiago de Cárdenas y su "calidad” subalterna en el marco de la sociedad de castas en el Perú.

16 Sobre la posibilidad de una inventiva americana (y no europea) argumentada por Cárdenas, resulta interesante observar la forma cómo cuestiona la expresión "Non plus Ultra" (con base en la leyenda de Hércules), pretendiendo desafiar ("Plus ultra”) los límites que impone la frontera epistémica del saber eurocentrado en el siglo XVIII: OBJECION 21. "D - Se me ha dicho que si el Bolar fuera pocible, lla en la Europa se ubiera descubierto por tanto onbre sabio especialmente en la Francia. C - A que se respondio que no prueba sea ynposible un descubrimiento porque asta aqui nos calla manifestando por que en todos los reinos i en todos los tiempos se acienta en dar tal Golpe de pinsel que se diga esto es lo ultimo " (1937, p.126-127). "Muchos años sabia que estaba poblado el mundo i no se abia descubierto este Nuebo y Basto Continente (...) asi Bamos corriendo la bida pareciéndonos al que dijo Nonplus Ultra pero Pul ultra disen las Comunas del tinbre Peruano. (1937, p.128). 